\title{
Effects of thickness reduction on recrystallization process of warm-rolled pure tungsten plates at $1350^{\circ} \mathrm{C}$
}

Wang, Kang; Zan, Xiang; Yu, Ming; Pantleon, Wolfgang; Luo, Laima; Zhu, Xiaoyong; Li, Ping; Wu, Yucheng

\section{Published in:}

Fusion Engineering and Design

Link to article, DOI:

10.1016/j.fusengdes.2017.03.140

Publication date:

2017

Document Version

Peer reviewed version

Link back to DTU Orbit

Citation (APA):

Wang, K., Zan, X., Yu, M., Pantleon, W., Luo, L., Zhu, X., Li, P., \& Wu, Y. (2017). Effects of thickness reduction on recrystallization process of warm-rolled pure tungsten plates at $1350^{\circ} \mathrm{C}$. Fusion Engineering and Design 125, 521-525. https://doi.org/10.1016/j.fusengdes.2017.03.140

\section{General rights}

Copyright and moral rights for the publications made accessible in the public portal are retained by the authors and/or other copyright owners and it is a condition of accessing publications that users recognise and abide by the legal requirements associated with these rights.

- Users may download and print one copy of any publication from the public portal for the purpose of private study or research.

- You may not further distribute the material or use it for any profit-making activity or commercial gain

- You may freely distribute the URL identifying the publication in the public portal 


\title{
Effects of Thickness Reduction on Recrystallization Process of Warm- Rolled Pure Tungsten Plates at $1350{ }^{\circ} \mathrm{C}$
}

\author{
Kang Wang ${ }^{1}$, Xiang Zan ${ }^{* 2,3,5}$, Ming $\mathrm{Yu}^{2}$, Wolfgang Pantleon ${ }^{4}$, Laima Luo ${ }^{2,3,5}$, Xiaoyong Zhu ${ }^{3}$, \\ Ping $\mathrm{Li}^{2}$, Yucheng $\mathrm{Wu}^{*} 1,2,3,5$ \\ ${ }^{1}$ Institute of Industry \& Equipment Technology, Hefei University of Technology, Hefei, Anhui, 230009, China \\ ${ }^{2}$ School of Materials Science and Engineering, Hefei University of Technology, Hefei, Anhui, 230009, China \\ ${ }^{3}$ National-Local Joint Engineering Research Centre of Nonferrous Metals and Processing Technology, Hefei, Anhui, \\ 230009, China \\ ${ }^{4}$ Department of Mechanical Engineering, Technical University of Denmark, Kgs. Lyngby, 2800, Denmark \\ ${ }^{5}$ Laboratory of Nonferrous Metal Material and Processing Engineering of Anhui Province, Hefei, 230009, China
}

\begin{abstract}
Investigations are conducted of the recrystallization behavior of pure tungsten through different thickness reductions by isothermal annealing at $1350{ }^{\circ} \mathrm{C}$. Concise description is made of the recrystallization kinetics by the Johnson-Mehl-Avrami-Kolmogorov (JMAK) model in combination with hardness test results. The rate of the recrystallization process increases with the deformation ratio. For further investigations, three boundary maps of tungsten plates which are of different thickness reductions by rolling and in full recrystallization are obtained, each covering an area of $1.15 \times 1.05 \mathrm{~mm}^{2}$ on the transversal section comprising the rolling direction ( RD ) and the normal direction ( ND ). The average grain size and its distribution of pure tungsten can be easily calculated, and hence the grain aspect ratios of pure tungsten.
\end{abstract}

Keywords: tungsten; recrystallization; Vickers hardness; microstructure; grain size distribution

\section{Introduction}

Nowadays, the fusion power reactor is drawing enormous attention as a future source of energy. However, it demands the availability of plasma facing materials that can withstand extreme conditions of temperature, irradiation and thermal stress. Pure tungsten is the most promising candidate for the first wall material and the diverter components in fusion reactors, which will be subjected to high heat peak loads up to $10-20 \mathrm{MW} / \mathrm{m}^{2}$ and temperature gradients[1], due to its high melting point, high strength at high temperatures, good thermal conductivity, low thermal expansion coefficient, high sputtering threshold energy and limited activation under neutron irradiation[2, 3]. Pure tungsten is generally manufactured through different technologies, including powder metallurgy and plastic deformation process[4]. In terms of physical metallurgy, plastic deformation leads to the increase of the internal stored energy[5]. At high temperatures, recovery, recrystallization and grain growth will occur in deformed tungsten. These microstructural changes will cause degradation of the material properties, such as a loss in mechanical strength, or even embrittlement, as is the most critical.

S.N. Mathaudhu studied the microstructural evolution and recrystallization mechanism of coarse grained tungsten during annealing after equiaxial angular extrusion[6]. A. Vorhauer studied the microstructural evolution and thermal stability of tungsten-based materials afetr large plastic deformation. SEM and BSM were used to study the microstructure evolution and crystal size distribution[7]. Alfonso, A. characterized the activation energy of pure tungsten during recrystallization by isothermal annealing and hardness degradation experiments and predicted the service life of pure tungsten at high temperatures through Arrhennius relationship, and established the kinetics of recrystallization model[8].

The present work investigates the effects of thickness reduction on the recrystallization behavior of pure tungsten at $1350{ }^{\circ} \mathrm{C}$. The changes in the mechanical properties during annealing are quantified by Vickers hardness measurements. The changes of hardness and volume fraction of recrystallization are described by a Johnson- Mehl-AvramiKolmogorov model.

\section{Materials and Methods}

Three warm-rolled pure tungsten plates with 50\%, 67\% and 90\% (subsequently referred to as W50, W67 and W90) thickness reductions were received from Beijing Tianlong tungsten Technology Co. Ltd. These plates were cut off from the same sintered billet to ensure the same initial sintered microstructures. Small specimens of $6 \times 7 \times 8 \mathrm{~mm}^{3}$ were cut off from the plates by wire-cut electrical-discharge machining. All samples were isothermally annealed for various durations of time at $1350{ }^{\circ} \mathrm{C}$. Prior to heat treatment, the specimens had been placed in an evacuated and sealed quartz tube to avoid oxidation.

${ }^{*}$ Corresponding Author: Xiang Zan, Yucheng Wu

E-mail: zanx@hfut.edu.cn, ycwu@hfut.edu.cn 
The hardness of the samples was measured with a load of $200 \mathrm{~g}$ for $10 \mathrm{~s}$ on the RD (Rolling Direction) $\times$ ND (Normal Direction or thickness direction) plane to evaluate the extent of recrystallization. In order to determine the hardness value, 10 measurements were carried out to obtain an average value for each sample. The reported hardness values $\mathrm{HV}_{0.2} \pm \Delta \mathrm{HV}_{0.2}$ are averages over 10 indents with the standard deviation $\Delta \mathrm{HV}_{0.2}$ of the average, as is represented by error bars in the graphs below. Prior to hardness tests, the examined surfaces were prepared metallographically by subsequent mechanical grinding and polishing with SiC papers (1000 \# in the final step) and polishing pastes, respectively. For the optical microscopic structure inspection, samples were etched with boiling $3 \% \mathrm{H}_{2} \mathrm{O}_{2}$ aqueous solution. Optical micrographs were obtained under polarized light to examine the RD $\times$ ND plane of the specimens.

\section{Results and discussion}

Generally, the kinetics of the softening process during the annealing process can be categorized into three main stages: recovery, recrystallization and grain growth. Recovery usually occurs at low temperatures and involves thermally activated motion, condensation, and annihilation of point defects and specifically annihilation and rearrangement of dislocations[5]. Here the recovery stage can be ignored due to the very short period of the recovery process at 1350 . Cn this study, only the process of recrystallization will be investigated.

Fig. 1 shows light optical micrographs of W50, W67 and W90 annealed at $1350{ }^{\circ} \mathrm{C}$ for selected times, which are the status of as-received, partially recrystallized and fully recrystallized microstructures. Obviously, with the increased deformation ratio, the shape of the crystal grains is more elongated and the grain size is smaller at as-received status. After fully recrystallization, the grain size is smaller with the increased deformation ratio. It reveals clearly that the deformation structure with elongated grains after warm rolling is replaced by a structure with equiaxed grains during the heat treatment process.
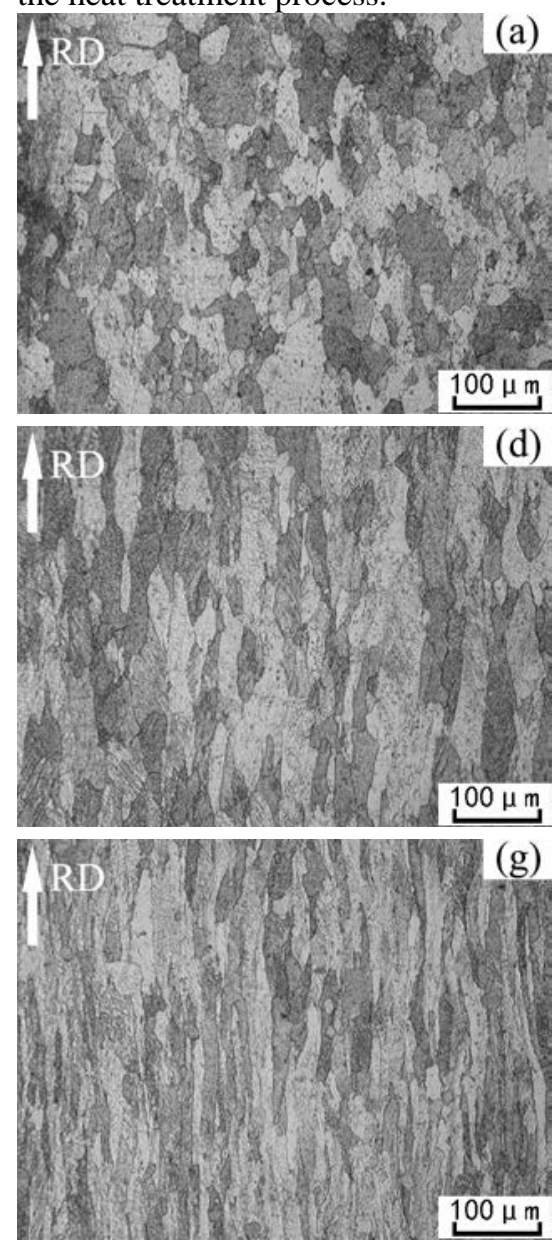
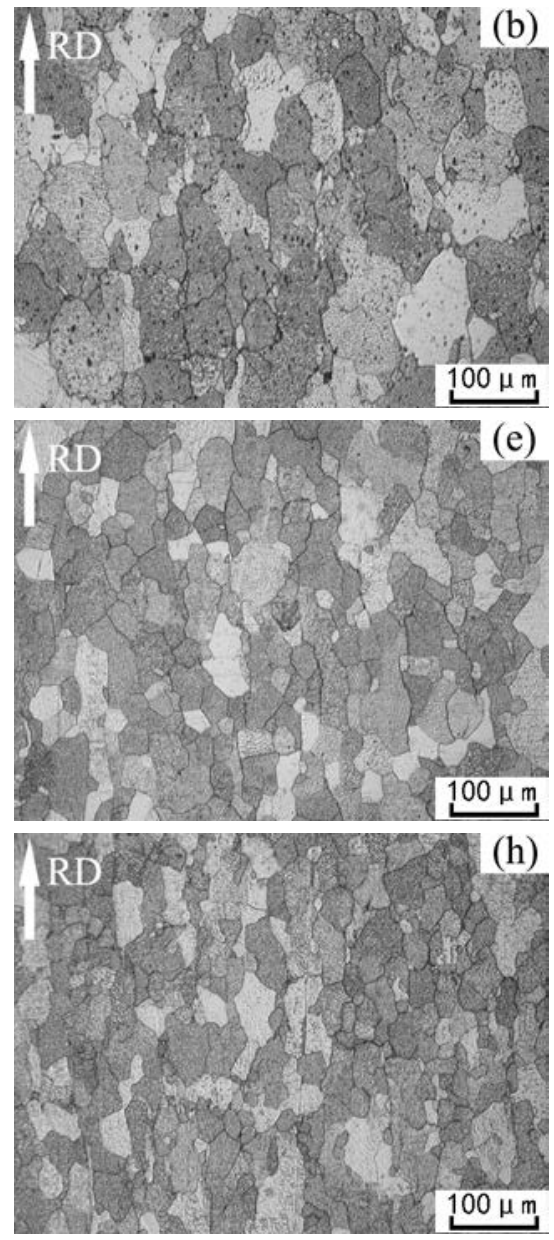
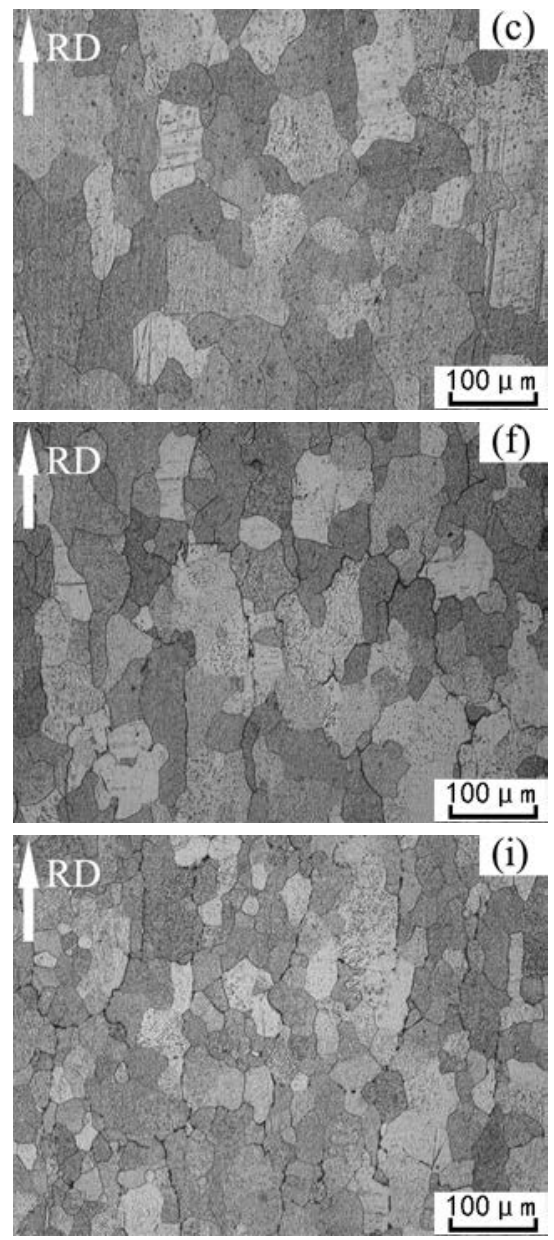

Fig. 1. Microstructural evolution of W50, W67 and W90 annealed at $1350{ }^{\circ} \mathrm{C}$ for various times:

(a) 0 h, (b) $3 \mathrm{~h}$ and (c)23h for W50; (d) 0 h, (e) $1.5 \mathrm{~h}$ and (f) $15 \mathrm{~h}$ for W67; (g) 0 h, (h) $1 \mathrm{~h}$ and (i) $11 \mathrm{~h}$ for W90.

The recrystallization process of the three plates through different thickness reductions is studied by using the measurements of Vickers hardness as a function of annealing time at $1350{ }^{\circ} \mathrm{C}$, as shown in Fig. 2. The Vickers hardness of as-received plates are 410.39 $\pm 3.6 \mathrm{HV}_{0.2}, 425.23 \pm 1.7 \mathrm{HV}_{0.2}$ and $429.41 \pm 2.0 \mathrm{HV}_{0.2}$ for W50, W67 and W90, respectively, indicating that the higher deformation ratio leads to higher values of hardness. Among the as-received plates, with the increased deformation ratio, the shape of the grains is more elongated and the grain size is smaller. At 
the same time, the storage energy and the dislocation density in the deformed grains increase within the deformation process, hence the hardness is larger. As the deformation ratio increases to a certain range, the hardness will not increase significantly. As shown in Fig. 2, the as-received hardness of W67 is larger than that of W50 but only a little bit smaller than that of W90.

The Vickers hardness decreases with the increased annealing time, e.g. the Vickers hardness of W67 decreases from $425.23 \pm 1.7 \mathrm{HV}_{0.2}$ in the as-received condition to $348.69 \pm 1.0 \mathrm{HV}_{0.2}$ in the fully recrystallized condition. The recrystallization rate increases with the thickness reduction from $50 \%$ to $90 \%$, owing to the larger strain energy stored in the plates as the deformation ratio becomes higher. The time of the full recrystallization reduces from $23 \mathrm{~h}$ for W50 to $9 \mathrm{~h}$ for W90. This proves that larger deformation can promote the recrystallization process. At a higher temperature, the effect of thickness reduction on recrystallization becomes relatively weak after the deformation reaches a certain value.

Since the hardness $(H V)$ is relate to volume fraction of recrystallized grains $(X)$, the $X$ can be calculated from the variation in hardness with annealing time as:

$$
X=\frac{H V_{r e c}-H V}{H V_{r e c}-H V_{r e x}}
$$

where $H V_{\text {rec }}$ is the hardness value of the as-received state and $H V_{\text {rex }}$ is that of the fully recrystallized state.

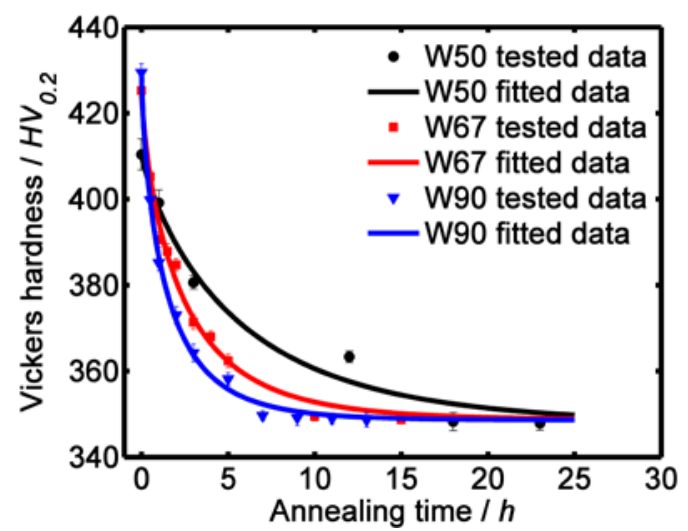

Fig. 2. Evolution of Vickers hardness of W50, W67 and W90 annealed at $1350{ }^{\circ} \mathrm{C}$ for different times

The volume fraction of recrystallized grains $(X)$ as a function of annealing time $(t)$ can be well described by the Johnson-Mehl-Avrami-Kolmogorov (JMAK) equation [9]:

$$
X=1-\exp \left(-b^{n} t^{n}\right)
$$

where the coefficient $b$ describes thermal activation and the exponent $n$ is related to the nature of nucleation and the dimensionality of nuclei growth [9]. As shown in Fig. 2, the experimental hardness data are fitted to annealing time by using Eqs. (1) and (2). The values of $b$ and $n$ are obtained by non-linear fitting, as shown in Table 1 . It is found that the coefficients $b$ and $n$ strongly depend on the thickness reduction, for, as the thickness reduction increases, the value of $b$ increases accordingly whereas the exponent $n$ decreases with the increase of thickness reduction. According to the JMAK equation, the value of $n$ depends very much on the type of nucleation and growth of grains. In the case of sitesaturated nucleation, the value of $n$ should be 3 for three-dimensional (3D) growth and 2 for 2D growth. In the case of continuous nucleation, the value of $n$ will be 4 for 3D growth and 3 for 2D growth [10]. But all the values of $n$ found in the present study are much lower than the theoretical values. Similar results are also reported in literature [11-13]. The reason that these values of the Avrami exponent $n$ are low is such that the JMAK model is unable to account for the heterogeneity of the recrystallization process [9]. The heterogeneous microstructures will lead to a non-random distribution of nuclei (due to the heterogeneous distribution of nucleation sites) and to different growth rates for the different individual grains (due to the stored energy of the surrounding recovered matrix and to the recovered matrixnucleus orientation relationship). 


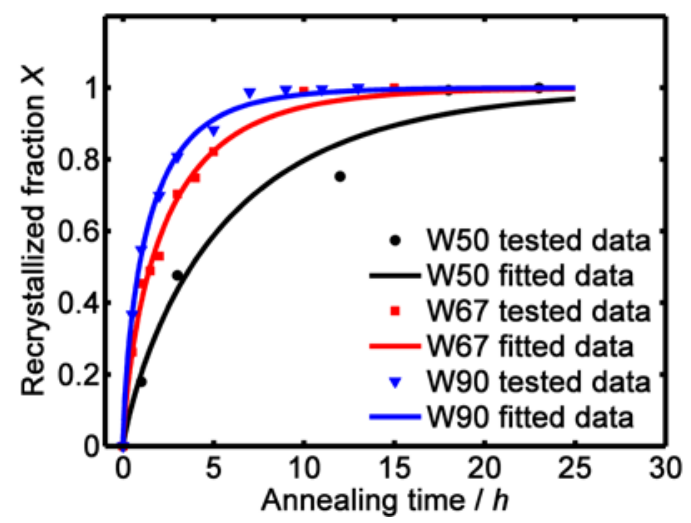

Fig. 3. Evolution of recrystallized volume fraction $X$ for W50, W67 and W90 during annealing at $1350{ }^{\circ} \mathrm{C}$

Table 1 Values of $b$ and $n$ for recrystallization kinetics of warm-rolled tungsten during isothermal annealing at $1350{ }^{\circ} \mathrm{C}$

\begin{tabular}{ccccc}
\hline Reduction (\%) & $H V_{\text {rec }}$ & $H V_{\text {rex }}$ & $b$ & $n$ \\
\hline W50 & 410.39 & 347.84 & 0.21 & 1.06 \\
W67 & 425.23 & 348.69 & 0.42 & 0.86 \\
W90 & 429.41 & 347.59 & 0.67 & 0.78 \\
\hline
\end{tabular}

For further studies of the grain size distributions after recrystallization, six metallographic photographs are spliced into a larger area of $1.15 \times 1.05 \mathrm{~mm}^{2}$ in order to increase the number of statistical samples and make the statistical results more accurate. Thus, the grain size distributions, the average grain size and the grain aspect ratios of W50, W67 and W90 in full recrystallization can be easily calculated. The boundary maps of W50, W67 and W90 in full recrystallization are shown in Fig. 4. In the maps, there are 288 grains for W50, 823 grains for W67 and 999 grains for W90, with all the grains on the borders excluded. The grain size distributions of pure tungsten are shown in Fig. 5, where the grain size is replaced by the equivalent circular diameter (ECD), which is calculated from the equation:

$$
D=2 \sqrt{\frac{A}{\pi}}
$$

where $A$ represents the area of each grain. The average grain size is determined by averaging the diameters of the entire section (area weighted average of the ECD). The obtained average ECD of W50, W67 and W90 in full recrystallization are $52.15 \mu \mathrm{m}, 30.67 \mu \mathrm{m}$ and $28.66 \mu \mathrm{m}$, respectively. Obviously, the average recrystallized grain size reduces as the thickness reduction increases, which can also be proved by observing Fig. 4 and Fig. 5.

After the recrystallization, the new strain-free grains of smaller dislocation density replace the deformed grains of high dislocation density. By using the Johnson-Mehl equation, it can prove that there is a relationship between the grain size $d$ and the nucleation rate $N$ and the growth rate $G$ :

$$
d=k\left(\frac{G}{N}\right)^{\frac{1}{4}}
$$

where $k$ is a constant. The stored energy of the driven nucleation and growth increases and the nucleation rate increases rapidly with the increased thickness reduction, which makes the $N / G$ become larger. So, the average recrystallized grain size reduced with the increased thickness reduction. But the hardness values of the fully recrystallized tungsten plates tend to be almost the same. The hardness values of W50, W67 and W90 are 347.84 $\pm 1.62 \mathrm{HV}_{0.2}, 348.69 \pm 1.00 \mathrm{HV}_{0.2}$ and $348.59 \pm 1.63 \mathrm{HV}_{0.2}$, respectively, in the fully recrystallized condition. This may be because the grains close to the non-distorted equiaxed grains and the dislocation density in the grains are reduced after fully recrystallization. In addition, Vickers hardness measurements used a load of $200 \mathrm{~g}$ and the indentation size is about $30 \mu \mathrm{m} \times 30 \mu \mathrm{m}$, which is approximately equal to or smaller than the grain size. The indentation mainly falls within the inner part of the grains and the grain boundary effect can be neglected. Thus, the hardness values are nearly the same in the fully recrystallized condition. 

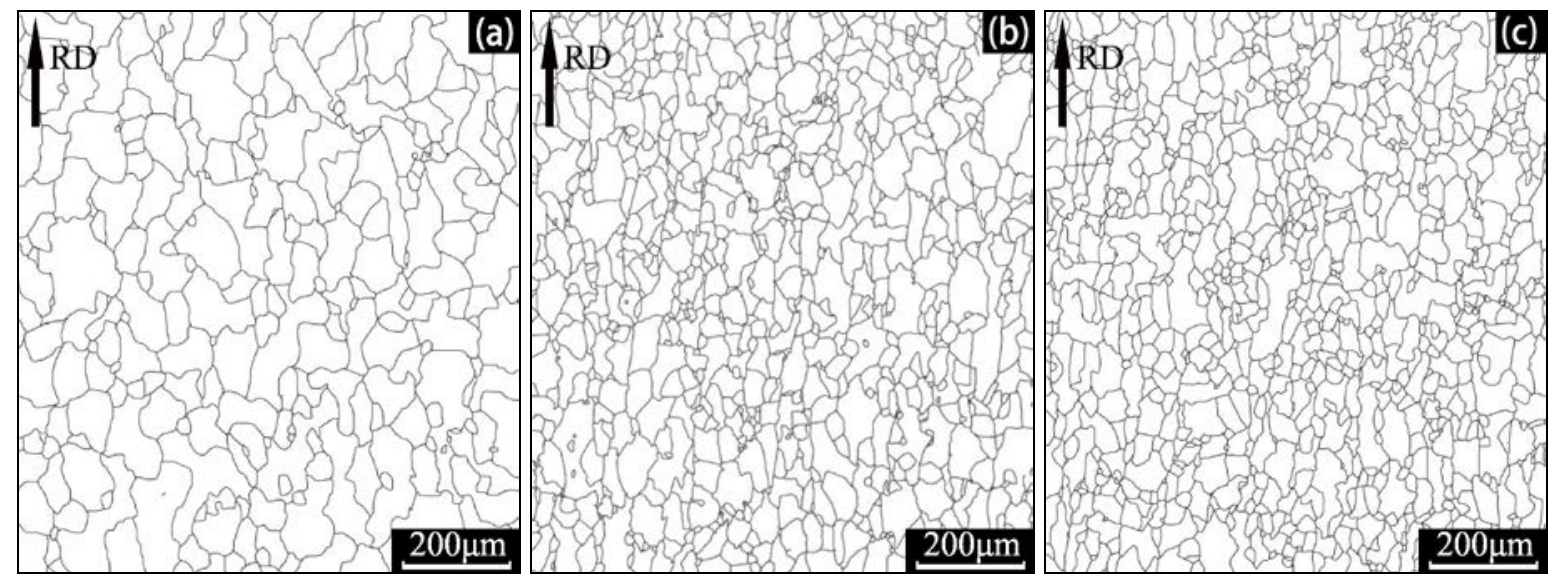

Fig. 4. Boundary maps of pure tungsten after annealing at $1350{ }^{\circ} \mathrm{C}$ for various times: (a) W50 for $23 \mathrm{~h}$, (b) W70 for $15 \mathrm{~h}$ and (c) W90 for $11 \mathrm{~h}$.
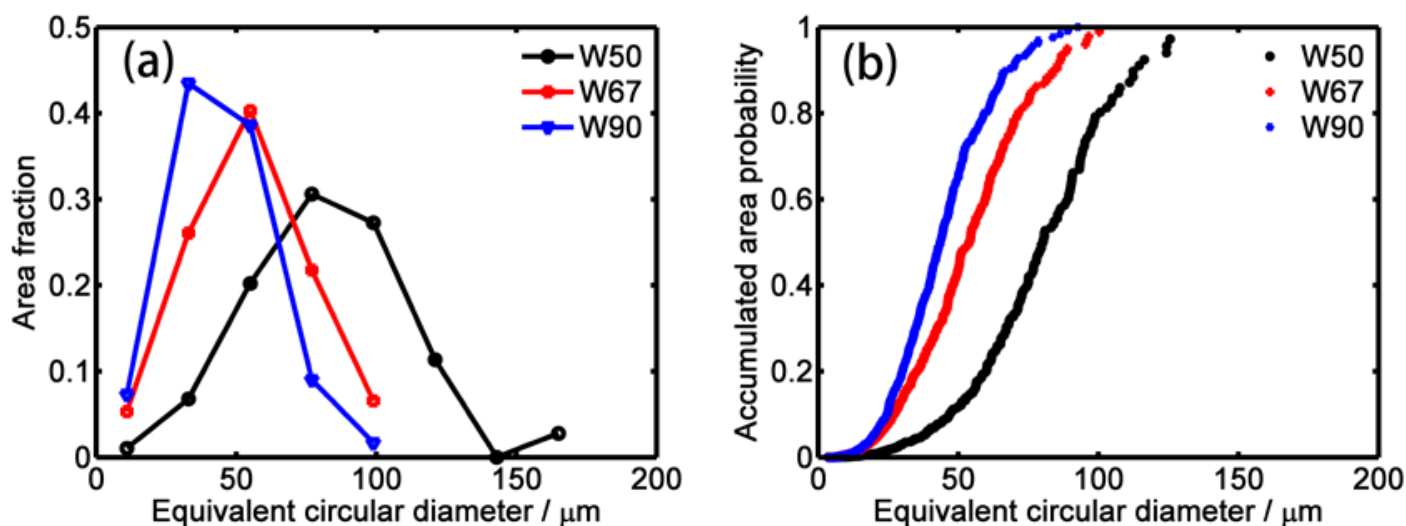

Fig. 5. (a) area fraction and (b) accumulated grain size probability of W50, W67, W90 fully recrystallized at $1350{ }^{\circ} \mathrm{C}$

Fig. 5a shows the grain size distributions of W50, W67 and W90 in the fully recrystallized state at $1350{ }^{\circ} \mathrm{C}$. The grain size distributions cover a wide range (for all thickness reductions). Such wide grain size distributions are typical for hot-deformed samples [14, 15]. The grain size distribution of W90 and W67 is much narrower than that of W50. The maximum grain size is about $100 \mu \mathrm{m}$ in the $\mathrm{W} 67$ and $\mathrm{W} 90$, but over $170 \mu \mathrm{m}$ in the W50. The curves of the grain size distribution of W67 and W90 is very close. The W50 grain size distribution is relatively dispersed. This is because there is a stored energy gradient within a grain or between neighboring grains when the deformation is small, which leads to non-random distribution of nucleation sites and reduces grain growth rate. Deformed grains with higher stored energy will recrystallize first and thus have higher nucleation probability to produce fine grains.

The accumulated frequency distributions of grain size in the fully recrystallized specimens as shown in Fig. 5b are constructed from the size data of Fig. 5a. From Fig. 5b, it can also be seen that the tendency of grain size distributions is similar for all thickness reductions. These distributions tend to shift to the right (to larger grain size) for smaller deformation. With the increase of thickness reduction, the original grain of tungsten plates becomes smaller and the grain size in full recrystallization is smaller too. 

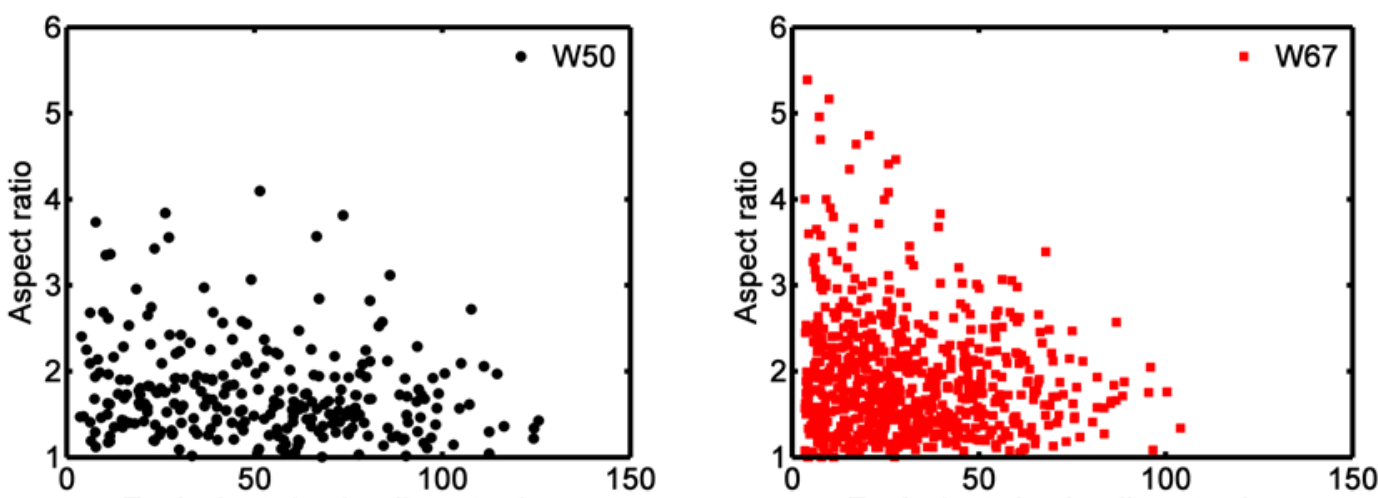

Equivalent circular diameter $/ \mu \mathrm{m}$

Equivalent circular diameter $/ \mu \mathrm{m}$

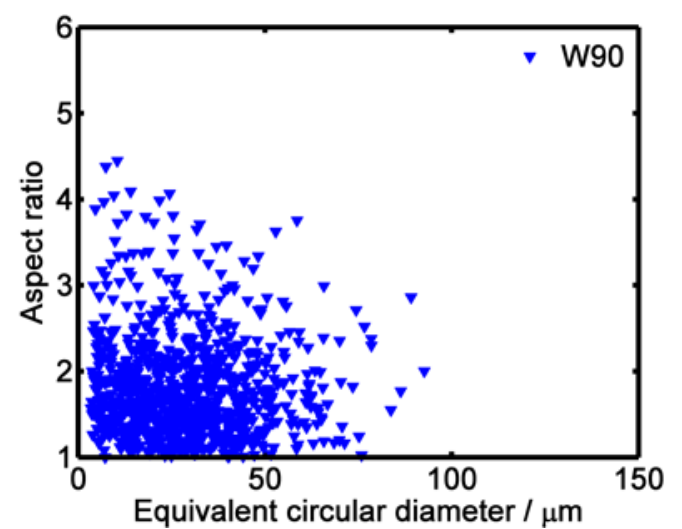

Fig. 6. Aspect ratio distributions of fully recrystallized W50, W67 and W90

The grain aspect ratios distributions of W50, W67 and W90 in full recrystallization are quantified in Fig. 6. It can be seen that the newly formed stress-free grains are close to equiaxial crystal. With the increased thickness reduction, the average fully recrystallized grain size reduces and the long axis of the grains increases.

\section{Conclusions}

The recrystallization behavior of pure tungsten through different thickness reductions (50\%, 67\% and $90 \%$ ) is investigated by means of Vickers hardness tests, OM and grain size distribution observations. Large thickness reduction is proved to accelerate the recrystallization process, which is evidenced by the hardness tests in combination with microstructural observations. It is found that the coefficients $b$ and $n$ in the JMAK model depend very much on the deformation ratio. As the thickness reduction increases, the coefficient $b$ increases whereas the exponent $n$ decreases. The grain size distributions of W50, W67 and W90 in the fully recrystallized state at $1350{ }^{\circ} \mathrm{C}$ are obtained. With the increase of the deformation ratio, the original grains of tungsten plates become smaller and the grains in the fully recrystallized state are smaller too. The aspect ratios of grains through higher thickness reduction seem larger than those at a smaller deformation ratio.

\section{Acknowledgments}

This paper was supported by National Magnetic Confinement Fusion Program with Grant No. 2014 GB121001 and National Natural Science Foundation of China with Grant No. 51474083.

\section{References}

[1] Rieth, M., Dudarev, S.L., Vicente, S.M.G.D., et al., Recent progress in research on tungsten materials for nuclear fusion applications in Europe, J. Nucl. Mater. 432 (2013) 482-500.

[2] Maier, H., Krieger, K., Balden, M., et al., Erosion and deposition in the ASDEX Upgrade tungsten divertor experiment, J. Nucl. Mater. 266 (1999) 1003-1008.

[3] Neu, R., Hopf, C., Kallenbach, A., et al., Operational conditions in a W-clad tokamak, J. Nucl. Mater. 367-370 (2007) 1497-1502.

[4] Valiev, R.Z., Islamgaliev, R.K. and Alexandrov, I.V., Bulk nanostructured materials from severe plastic deformation, Prog. Mater. Sci. 45 (2000) 103-189.

[5] Raabe, D., Recovery and Recrystallization: Phenomena, Physics, Models, Simulation, Physical Metallurgy (Fifth Edition). Elsevier, Amsterdam (2014), pp. 2291-2397. 
[6] Mathaudhu, S.N., Derosset, A.J., Hartwig, K.T., et al., Microstructures and recrystallization behavior of severely hot-deformed tungsten, Mater. Sci. Eng., A. 503 (2009) 28-31.

[7] Vorhauer, A. and Pippan, R., Microstructure and Thermal Stability of Tungsten Based Materials Processed by Means of Severe Plastic Deformation, Mater. Sci. Forum. 426-432 (2003) 2747-2752.

[8] Alfonso, A., Jensen, D.J., Luo, G.N., et al., Recrystallization kinetics of warm-rolled tungsten in the temperature range $1150-1350^{\circ} \mathrm{C}$, J. Nucl. Mater. 455 (2014) 591-594.

[9] Humphreys, F.J. and Hatherly, M., Abbreviations - Recrystallization and Related Annealing Phenomena (Second Edition), 2004.

[10] Tian, H., Wang, X., Gong, W., et al., Recrystallization behavior of cold-rolled Zr-1Nb alloy, J. Nucl. Mater. 456 (2015) 321-328.

[11] Khalifa, H.E. and Vecchio, K.S., Thermal stability and crystallization phenomena of low cost Ti-based bulk metallic glass, J. Non-Cryst. Solids. 357 (2011) 3393-3398.

[12] Lin, F.X., Pantleon, W., Leffers, T., et al., Effects of Initial Parameters on the Development of Cube Texture during Recrystallization of Copper, Mater. Sci. Forum. 702-703 (2011) 398-401.

[13] Sun, N.X., Liu, X.D. and Lu, K., An explanation to the anomalous avrami exponent, Scripta Mater. 34 (1996) 1201-1207.

[14] Mingard, K.P., Roebuck, B., Bennett, E.G., et al., Grain size measurement by EBSD in complex hot deformed metal alloy microstructures, J. Microsc. 227 (2007) 298-308.

[15] Mingard, K.P., Roebuck, B., Bennett, E.G., et al., Metrological aspects of Electron Backscattering Diffraction in characterising hot deformation grain structures, Mapan-J. Metrol. Soc. I. 22 (2007) 177-200. 